There is considerable difficulty in keeping this organism alive, but it can be done by transplanting it on Loeffler's serum every three or four days, and keeping it constantly at $37^{\circ} \mathrm{C}$. Cultures on Loeffler's serum kept at $37^{\circ} \mathrm{C}$. were alive after fourteen days, and grew on transplantation.

\section{A CASE OF HAMORRHAGIC PANCREATITIS.} JOHN C. UHTHOFF, and EDWARD F. MAYNARD, M.D.Lond., M.R.C.P.,

THE following case was read before the meeting of the British Medical Association held at Brighton in March of this year, but the details have not been published hitherto; as these cases are, however, being regarded with an interest only equalled by the increasing interest taken in all abdominal cases of recent years, it has been thought advisable to bring the following particulars forward.

The patient was a man, aged 77 ; very stout; his general health had been good, but latterly he had complained somewhat of symptoms of "indigestion." He was first geen on January 31st, 1900. He had felt well on getting up in the morning, and ate a bloater for his breakfast. The bowels acted as usual about 9 A.M. About I I A M. he was suddenly seized with pain in the abdomen, followed by sickness and collapse. The vomiting continued more or less constantly until death, the vomited matter consisting chiefly of "coffee grounds;" at first it was thought that the blackish particles might be portions of prunes which he had eaten the previous night. In the evening he was somewhat better; the abdomen was tender, but not distended; there was a slight hardness in the right iliac fossa, but no tenderness here, and the whole abdominal wall moved normally.

On February ist the symptoms continued much the same. The abdomen was slightly distended. The possibility of intestinal obstruction was taken into consideration, but no surgical procedure was thought advisable. In the evening he became suddenly collapsed, but recovered again after two or three hours. The temperature was $99^{\circ}$ to $100^{\circ}$; the pulse 120 .

On February and his condition remained unchanged, he having quite recovered from the collapse of the preving evenling, but in the evening this recurred, and now he had a zunning, uncountable, and irregular pulse, with subnormal temperature and profuse perspirations.

He again rallied from this attack of collapse, but never completely, and during the following afternoon (February 3 rd) he had $a$ third attack of collapse from which he did not rally, and to which he succumbed during the night. No further abdominal symptoms than those already mentioned presented themselves. As regards treatment, nutrient injections were given and hypodermic injections of strychnine and digitalis.

Necropsy. - The abdominal wall was very fat, about I inch in thickness. On opening the peritoneum numerous small white flat spots (fat necrosis) about the size of two pins' heads were seen on the intestinal peritoneum and the surface of the omentum. No sign of peritonitis was encountered until the lesser sac of the peritoneum was opened, when some bloodstained fluid was found, and a large, bulging, dark purple, cystic-looking object was seen pushing the peritoneum forwards; this object was about the size of an orange, and was the head of the pancreas. The entire organ was firmly adherent to adjacent structures, and was with very great difficulty removed whole. Scattered over its surface throughout its whole length were small spots of fat necrosis; the organ was considerably enlarged, in thickness rather than in length, especially its head. On making a section the capsule was observed to be thickened and tough. One large hæmorrhage about $3 \mathrm{~cm}$. in diameter was seen in the head of the gland, and smaller hæmorrhages were scattered throughout its entire length, with the exception of about 2 inches at its tail end; there was also a hæmorrhage on its inferior surface immediately under the capsule, this being most marked on the middle third of the body, and also another on the posterior aspect of the head. Deposits of yellow fat were found taking the place of normal tissue in many parts of the gland.

By an unfortunate mistake the specimen was not properly preserved for microscopical or bacteriological examination.

\section{NOTES ON A CASE OF ACUTE PANCREATITIS} COMPLICATING MUMPS.

\author{
BY HENRY W. JACOB, M.A., M.D., \\ Great Malvern.
}

I HAVE recorded this case on account of the rarity of this complication of mumps.

J. S., aged to (schoolboy) is the only child of healthy parents. He has occasionally suffered from bronchitis, and had subacute rheumatism with slight endocarditis (?) in 189, from which he recovered completely. On March $3^{\text {rst, }}$ roo, he complained of sore throat, headache, and general malaise, accompanied by pain and stiffness about the angles of the jaw, especially on tue left side. On examination the left parotid gland was temperature was $100^{\circ}$, and his pulse 90 . On Appil 2 nd the tenperature was ${ }^{\circ}$. there was much more pain in the parotid glands, and the was ror. 4 ; there was much more pain in the parotid glands, and the were tender and considerably enlarged; the tongue was covered with $a$ pasty white fur, and the skin was dry and hot. The diagnosis was sufficiently obvious from the boy's symptoms and appearance, but it may also be noted that several boys from the ing from mumpe.

On the morning of April $3^{\text {rd }}$ he was sick, and continued to vomit at short intervals during the day. The vomiting was so severe that the smallest quantities of milk and water were rejected. During the day he with a lained of some pain in the stomach, and about ro P.M. he was sezed with a very violent pain in the upper part of the abdomen; the vomiting
still continued, and after each attack the pain was slightly less for a briee period pt I2 P.M. I found him lying on his back in a condition of evidently acute suffering; but the knees were not drawn up and the abdomen did not appear to be much distended generally. The temperature had run up to 103. $8^{\circ}$, and the pulse to 120 ; the tongue was covered with a thick, white creamy fur, the skin was very dry, and the face wore an expression of intense anxiety, especially when any attempt was made to examine the abdomen. The swelling of the parotids was now distinctly less than it had been on the previous day, and pressure over the parotid region did not appear to cause so much pain as before; the submaxillary glands were, however, quite tender and somewhat enlarged, a fact which I did not observe on previous examinations.

On examination of the abdomen no increase of liver dulness could be detected, although the edge of the liver could be felt and was tender to the touch. Below the liver a narrow area was clear on percussion, and was not markedly tender to pressure; below this clear area and separated $b y$ it from the lower border of the liver a sausage-shaped mass could be distinctly felt, which was exquisitely tender on pressure, and extended from within the epigastrium slightly upwards and to the left into the left hypochondrium, exactly in the position in which one would expect to find an enlarged pancreas. On pressing as firmly as could be borne over this mass a dull note was elicited by percussion, but when the finger percussed was only lightly laid on the surface a somewhat resonant note could be
heard.indicating that the mass was in all probability situated behind the heard,ind stomach

The swelling did not move with respiration, but could be slightly could not be well mapped out; in the right hypochondr'um the note was clear on percussion.

There was nopain or tenderness in the lower region of the abdomen and except for the tenderness noted in the lower border of the liver al pain and tenderness was strictly limited to the dull area beneath which the sausage-shaped swelling could be felt. I arrived at the conclusion that the mass was an enlarged pancreas which was undergoing so-called metastatic inflammation in the course of a case of mumps just as in certain cases the testis is similarly affected.

Turpentine fomentations were applied to the seat of pain, and one grain of calomel and three grains of Dover's powder given; the powder was administered in very hot water; a little later sips of hot water were given, $a$ small quantity of bicarbonate of soda being dissolved in the hot water ; the patient liad no vomiting after the administration of the medicines until several hours later, when be vomited once: a diaphoretic mixture was given, and a dose of castor oil (half an ounce) was ordered to be given of the bowels that day, the motions being copious and offensive

After the bowels had, acted, the pancreatic swelling remained unaltereơ but in consequence of diminution of tenderness it was possible to determine the outlines of the organ with certainty. The temperature had fallen to roo. ${ }^{\circ}$, and the parotid glands appeared to be almost normal. The pain in the pancreatic region

On Thursday, April sth. the pain had quite gone, and the temperature had fallen to $07.8^{\circ}$, but for several days after this the pancreatic enlargement could still be felt, and some tenderness elicited on pressure.

On April roth (one week from the onset of the abdominal complication and eleven davs from the commencement of the attack of mumps) al tenderness had disappeared. and it was no longer possible to make ou any abnormal condition in the abdomen. The urine was examined both during and after the attack, and it contained no albumen or sugar.

The boy made an excellent recovery, and is now (April 2oth) apparently quite well, although slightly anæmic; his appetite is good, and his digestion does not appear to have suffered from the attack. It will be interesting to observe whether any symptoms indicative of atrophy of the pancreas occur in the subsequent history

The case appears to me to be of interest for several reasons : First, the rarity of the affection; I cannot find any record of acute pancreatitis occurring as a complication of mumps. Secondly, the rapid onset and violent character of the com- 